\title{
DEPUIS project: Design of Environmentally- friendly Products Using Information Standards
}

\author{
Anna Amato ${ }^{1}$, Anna Moreno ${ }^{2}$, and Norman Swindells ${ }^{3}$ \\ ${ }^{1}$ ENEA, Italy, anna.amato@casaccia.enea.it \\ ${ }^{2}$ ENEA, Italy, anna.moreno@casaccia.enea.it \\ ${ }^{3}$ Ferroday Limited, UK, ns@ferroday.co.uk
}

\begin{abstract}
The design of environmentally friendly products requires data to assess the impact of the product on the environment throughout its life and the original design and manufacturing information that should accompany the product to manage the end-of-life process. Both of these requirements can be satisfied by the innovative combination of two groups of International Standards. The DEPUIS project provides e-learning systems to introduce the technology of data representation by standardised information models - product data technology - and shows how the information represented by data specified by these models can be used in Life Cycle Assessment to innovate life-cycle thinking in the design and manufacture of new products
\end{abstract}

Keywords: Life cycle assessment, product data technology, international standards, e-learning, innovative design

\section{Introduction}

DEPUIS (Design of Environmentally-friendly Products Using Information Standards) is a European funded project launched on the 1st September, 2006. The objective of DEPUIS is to support innovation in the environmentally-friendly design of new products and services through the use of standardised information models. The DEPUIS project is part of the Europe-INNOVA network [1] in the Sixth Framework Programme.

The project has two main actions:

- the provision of e-learning in product data technologies and the opportunities created by the ISO TC184/SC4 information standards and also by ISO 14048 and other ISO 14000 standards; 
- workshops to achieve interaction between users and developers of the standards to speed up the acceptance and dissemination of the new methods.

The outcomes from the workshops will be used to prepare policy recommendations to ISO and CEN in the areas of further standardization and innovation for reducing environmental impacts.

The main strategic objective of this project is to enable more companies, particularly SMEs, to use Life Cycle Thinking (LCT) on the environmental impact of their design of new products, in conformance with the Communication on Integrated Product Policy (IPP) [2] of the European Commission. Eco-innovation has to rely on the accessibility on environmental data during the whole life cycle of the product; therefore, standard product data models to integrate the necessary information about materials and processes are needed. [3] These standards and their technologies are important for the data representing the environmental information for sustainability because:

- data for making decisions about sustainability and the impact on the environment is generated in individual computer systems;

- this data has to be shared and exchanged between many different organizations with different systems and applications with many different methods of working;

- the data has to be conserved for longer than the lifetime of any computer system or software application;

- the data needs to be used and understood by unknown systems at unknown times in the future.

\section{Life Cycle Assessment (LCA)}

The environmental innovation of products is recognized as one of the principal instruments for the promotion and integration of competitiveness, innovation and sustainability that are key priorities for the European Union (COM(2004) 38 final) [4], (COM(2003) 302 final), (EC, 2004) [5].

The life-cycle of a product is often long and complicated. It covers several areas and phases involving many different actors such as designers, industry, marketing people, retailers and consumers. IPP attempts to stimulate each part of these individual phases to improve their environmental performance.

The term 'life cycle' refers to the notion that a fair, holistic assessment requires the assessment of raw material production, manufacture, distribution, use and disposal including all intervening transportation steps necessary or caused by the products 
existence. The sum of all those steps - or phases - is the life cycle of the product. The concept also can be used to optimize the environmental performance of a single product (ecodesign) or to optimize the environmental performance of a company.

Life Cycle Assessment (LCA) is an internationally standardised method (ISO, 2006) [6] for the evaluation of the environmental impact. It helps to avoid the "shifting of burdens" from one life cycle phase to another, among the various environmental implications, and to evaluate the options for improvement.

LCA is increasingly being used at the design stage of new products, where the need for changes can be more easily identified and the cost of making those changes is a minimum. Both retrospective assessment and LCA at the design stage need access to data and this will usually need to be collected from different sources and used in combination in an engineering computer system. However, different sources will have developed their data systems using different software and system platforms and each data system will therefore have a different internal representation for the data that it contains. The result is that data from different sources cannot be combined and used efficiently without a great deal of uncertainty, extra work and additional costs. The potential benefits of being able to use a combination of LCA data systems in the EU are therefore presently difficult to be achieved. In the field of LCA the agreement on the format of the data has been published as the international standard ISO 14048 (ISO, 2002) [7]. As the LCA is a method for assessing the environmental impact of a product through all of its life-cycle stages it requires a massive use of materials and processes data. On the other side, all the data are generated with electronic means by the users which hardly use any standard. The most important issues are therefore to achieve accessibility, comparability and quality assurance of data used in LCA of products and the integration of LCA in the design process.

\section{Product data technology}

The production and management of product information is every company's second business. Whereas most attention is paid to the management of the physical product throughout the lifetime, it is important to realize that the information that accompanies the product through its life is also important. It is well understood that the inputs and outputs of physical products have to managed by strict adherence to engineering specifications: otherwise there will be additional costs arising at a result of returns, rework, negotiations, etc. The same is true of product information. Inputs and outputs of technical information in the form of data associated with the product and its manufacturing processes have also to be managed by the equivalent of engineering specifications: otherwise costs will be incurred from the same causes as with the hardware.

International Standards for product data representation are the equivalent engineering specifications that provide a neutral mechanism for describing product data throughout the life cycle of a product and that are independent of any particu- 
lar software system. The nature of this description makes it suitable for neutral file exchange between different computer systems but also as a basis for implementing and sharing product databases and long-term archiving. Just as with standards that are engineering specifications for hardware, these product data standards can be used as the basis for quality control and quality assurance of product data and so ensure its validity and reliability.

The standards for product data technology provide information models for particular application domains that are independent from proprietary software. The benefits are that each software system needs only to have one only conversion interface, between its own internal structure and the independent model, to be able to output data or to use the information that is specified in a received model.
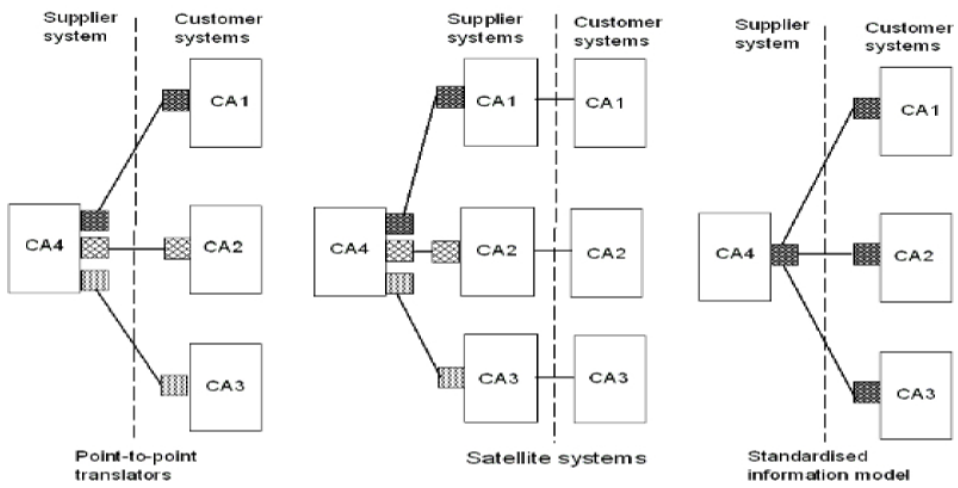

Figure 1 Alternative strategies for the communication between different computer software systems are shown in the figure above and illustrate the situation of a supplier with multiple customers (one-to-many and many-to-one)

Product data technology has been developed by the Sub-committee 4: Industrial data (SC4), of the ISO Technical Committee 184: Industrial automation systems and integration (TC184). ISO TC184/SC4 has developed the system of standards for the computerised representation of product and process data through the combined efforts of hundreds of engineers from the world's main industrialised nations and from most of the global industrial sectors.

The main standards of product data technology that are important for the whole life approach are:

- ISO 10303 Product data representation and exchange - the basis of the technology with generic information models and applications that satisfy particular industrial requirements (collectively known as STEP): 
- ISO 13584 Parts libraries - information model for dictionaries of terms that can be referenced from ISO 10303 (collectively known as PLib);

- ISO 15926 Integration of life-cycle data for process plants including oil and gas production facilities - a reference data library that defines the terminology for products that are used in chemical process plant and off-shore oil and gas construction projects (collectively known as RDL).

\subsection{ISO 10303 - Product data representation and exchange}

ISO 10303 is a very large collection of standard documents that provide the base technology for methods for the representation of product data and specify many of its applications [8]. The collection of documents is divided into groups of numbered parts that fulfill related roles. Parts 40 to 60 are the Integrated Generic Resources that are the fundamental basis from which all applications of ISO 10303 are developed. Together these Parts constitute a single information model, although the division into separate documents has been made for ease of their development and maintenance.

Parts 200 and upwards are the Application protocols of ISO 10303 that are implemented in engineering software for industrial use. Each Application protocol is an extension of the single model in the Integrated Generic Resources that has been specialised for a particular industrial need. For the whole-life approach, a selection of probably the most relevant applications is:

- ISO 10303-203: Configuration of 3D designs of mechanical parts and assemblies;

- ISO 10303-210: Electronic assembly, interconnection and packaging design;

- ISO 10303-214: Core data for automobile design processes;

- ISO 10303-235: Engineering properties for product design and verification;

- ISO 10303-239: Product life cycle support.

\subsection{ISO 13584 Parts Libraries}

ISO 13584 specifies an information model for classifications of products, or processes, and their associated properties. The importance of this model is that it has proved to be also very valuable for the compilation of dictionaries of terms that can be accessed by reference from the application models of ISO 10303. The benefit is that the information models in the applications of ISO 10303 can be 
sufficiently abstract that they can be used in many different industrial situations but the terminology used in a particular domain can be defined in a dictionary that conforms to ISO 13584.

Applications of ISO 13584 are made easier by the availability of free software that implements the information model and provides a simple user-interface for the input of data. The software is called PLIB Editor and it is supplied by the University of Poitiers [9].

\subsection{ISO 15926 Integration of life-cycle data for process plants including oil and gas production facilities}

ISO 15926 has been developed to overcome proprietary and system dependent data definitions that prohibit the effective exchange, sharing and integration of information, particularly, but not exclusively, in large construction projects. This international standard is based on an ontology and first order logic and has a generic concept model.

ISO 15926 is generic and defines a methodology for general handling of information data. It consists of several parts, Part 2 is the data model that defines the rules and the schema, and Part 4 contains the Reference Data Library (RDL). The RDL defines the semantic meaning of the terms used in a specific industry. An integrated information platform across disciplines can be established by extending the RDL of ISO 15926. Part 7 is implementation methods, which consists of templates and facades.

\section{Application of product data technology standards to LCA data}

The application of product data technology standards to the representation of lifecycle assessment data was successfully realised in the CASCADE Project of the European Commission [10]. The data fields defined in ISO 14048 were mapped onto the Reference Data Library of ISO 15926 and also onto the relevant data objects in ISO 10303-235: Engineering properties for product design and verification.

The CASCADE Project showed that there were no obstacles for the use in LCA of the representation of data for products, processes and their properties using the standards that have developed by ISO TC184/SC4. The unambiguous representations provided by these standards have advantages for computer-to-computer communication compared to other methods. 


\section{The DEPUIS Project}

The EU Project DEPUIS - Design of Environmentally Friendly Products Using Information Standards has the objectives of enabling more companies to adopt the approach of the IPP and to enable more people to develop the awareness and knowledge to put this approach into practice. The method adopted to achieve these objectives is the creation of a web site that has two main sections:

a multi-media handbook on the standards for LCA and product data technology and which provides other useful information;

e-Learning courses to enable more SMEs and software developers to adopt IPP environmental tools such as Life Cycle Assessment and Eco-design with the aim of achieving and marketing environmentally-friendly products. The e-learning courses are free of charge.

The web site [11] is hosted by ENEA - the Italian national research organization for new technology, energy and the environment.

The aims of DEPUIS are also to provide basic knowledge for software developers to help them to produce software compatible with International Standards, and to provide feedback to the standards developers.

The multi-media handbook is a compilation of information from many sources that is also frequently updated. The main components are:

- Interested Parties registration

- Examples of application of PDT and LCA integrated approach

- Searchable data base for standards

- Searchable data base for good practices

- Searchable data base for courses

- Certification and training system

- FAQ

- Other useful stuff

The Handbook includes a self-evaluation questionnaire, as a tool to promote the awareness among SMEs on the need of a good product data management. It is composed of seven sections about the following issues:

- Interoperability

- Data archiving

- Environmental data management 
- Materials data availability

- Knowledge of existing standards

- Training, qualification and certification

The self training learning courses allow anyone, anytime and anywhere, to gain the knowledge they need in order to participate in the workshops in a proactive manner. Workshops will suggest how to improve and how to implement what the Standards experts on PDT have developed and will be organized in the second half of the project when the multimedia handbook, the guidelines and the tutoring have been consolidated and the participants in the workshops should be more prepared in PDT and LCT. The courses are realized using a model set up by ENEA The methodology utilised by ENEA has been considered among the best 10 practices at international level by CEN ISS [12]. Each course is organized into a series of modules. The desired levels of attainment that have been identified for the each of the subjects in product data technology are one of:

- Awareness - familiarity with the scope and benefits of the technology;

- Knowledge - understanding of the principles and practice of the technology and the details of the scope of the standards;

- Skills - able to put the technology to use in engineering software.

The attainment of the Awareness level provides an introduction to everyone and would also be an appropriate level for managers and decision makers to reach. The attainment of the Knowledge level would be appropriate for design and project engineers, university academics and their students, IT managers, environmental consultants. The attainment of the Skills level would be appropriate for software engineers and their managers who implement the standards.

\section{Conclusions}

The DEPUIS Project has shown that there is a strong interaction between wholelife thinking and product data technology. The management of data throughout the life time of a product requires new methods that do not depend on the life-cycle of proprietary software and computer systems. Product data technology is available for this purpose now and new research is not needed in order to produce a solution to the problems of life-cycle data management.

There are now enough applications of product data standards to support:

- a supply chain of data both to and from accumulations of LCI data sets; 
- support for the measurement of environmental data with an audit trail to provide validation;

- support for recording the changes in the life of a product as maintenance replaces components;

- detailed descriptions of complex product that will support end-of-life strategies.

The DEPUIS project has developed a distance learning system as well other useful tools in order to enable individuals and enterprises to learn about the estimation of the environmental impacts of their products and processes and to introduce product data technology based on the International Standards for specifying the technical data for products that these estimations require.

DEPUIS also promotes the use of the standards by raising awareness about the benefits of a consequent better management of the products from every point of view: reduction of time to market, reduction of mistakes, better maintenance services and, in the end, lower costs of production, which is a goal of every company.

\section{References}

1. http://www.europe-innova.org/index.jsp

$2 \mathrm{http} / / /$ europa.eu.int/comm/environment/ipp/home.htm

3 Swindells, N, Moreno, A: Standards to support a sustainable world. A response from ISO TC184/SC4 to the Communiqué to ISO Committees on sustainability (2007)

4 COM (2004) 38 final, Commission of the European Communities, Stimulating Technologies for Sustainable Development: an Environmental Technologies Action Plan for the European Union, Communication from the Commission to the Council and the European Parliament, Brussels, 28 January.

5 COM (2003) 302 final, Commission of the European Communities, Integrated Product Policy. Building on Environmental Life-Cycle Thinking, Communication from the Commission to the Council and the European Parliament, Brussels, 18 June.

6 ISO 2006, ISO 14040:2006 Environmental management - Life cycle assessment - Principles and framework.

7 ISO 2002, ISO/TS 14048:2002 Environmental management - Life cycle assessment - Data documentation format.

8 http:://www.tc184-sc4.org/titles/STEPtitles.htm

9 http://www.plib.ensma.fr

$10 \mathrm{http}: / /$ www.pdt.enea.it

$11 \mathrm{http}: / / \mathrm{www}$. depuis.enea.it/

12 CEN 2007, Providing good practice for E-Learning quality approaches, CEN Workshop Agreement February 2007. 